\title{
Carotenoid-binding proteins; accessories to carotenoid function*
}

\author{
Jodi Pilbrow $\bowtie$, Daniel Garama and Alan Carne \\ Department of Biochemistry, University of Otago, Dunedin, New Zealand
}

\begin{abstract}
Understanding of the widespread biological importance of carotenoids is increasing. Accompanying this is the developing recognition that the interaction of carotenoids with other molecules, such as proteins, is also essential. Here the significance of carotenoid-protein interactions with respect to biological function is reviewed for three well characterised carotenoprotein complexes; crustacyanin, the orange carotenoid protein and glutathione-S-transferase $\mathrm{P} 1$. In addition a preliminary report is made on the recent partial purification of an echinenone-binding protein extracted from a New Zealand sea urchin, Evechinus chloroticus.
\end{abstract}

Key words: carotenoprotein, crustacyanin, orange carotenoid protein, glutathione-S-transferase P1, Evechinus chloroticus, echinenonebinding protein.

Received: 17 October, 2011; accepted: 01 March, 2012; available on-line: 17 March, 2012

An ever-increasing number of carotenoids (over 700 (Britton et al., 2004)) have been discovered in nature representing a diverse range of biological functions. These include: pigmentation for camouflage or display, photoprotectants and accessories to light harvesting complexes, antioxidants and precursors to visual pigments. There is also increasing evidence that carotenoids may have roles in the protection against many serious diseases such as cancer, heart disease and age-related macular degeneration (AMD) (Britton, 1995; Bernstein et al., 2002).

Despite their highly hydrophobic nature carotenoids are ubiquitous in aqueous cellular environments. This presents a challenge for the organism, as it is desirable to prevent inappropriate aggregation and crystallisation in order to maintain functionality. To enhance solubility, carotenoids form complexes with other molecules, often proteins, or with lipids as in membranes. Immersed in the hydrophobic core of the lipid bilayer the carotenoid is solvent protected by the amphiphilic nature of the phospholipids (Britton, 2008). Similarly, when transported through plasma carotenoids are incorporated into lipoproteins (Erdman et al., 1993). Numerous carotenoids may also assemble with lipo(glyco)proteins forming high molecular weight complexes such as the lipovitellins (Zagalsky, 1976). Conversely, water-soluble carotenoprotein complexes are usually of comparatively lower molecular weight, most varying between less than $20 \mathrm{kDa}$ (Cháberra et al., 2011) and $100 \mathrm{kDa}$ (Britton \& Halliwell, 2008). In addition, the ligand-protein interaction is highly specific and generally stoichiometric (Britton \& Halliwell, 2008).

The environment of a carotenoid can significantly affect its chemical and physical properties (Britton \& Halliwell, 2008). The lipocalin protein family, to which most carotenoid-binding proteins (CBPs) belong, have a tertiary structure that buries the chromophore deep within a pocket of hydrophobic residues (Flower, 1996). The strong non-covalent ligand-protein interactions can result in perturbation of the carotenoid electronic structure (Britton \& Halliwell, 2008). Such interactions may have originated out of necessity, but it now appears that evolution has produced a complex cooperative and functionally interdependent relationship. The subtleties of this symbiosis are manipulated by organisms, providing a number of elegant systems that uniquely exploit and enhance the properties of carotenoids. The orange carotenoid protein (OCP), glutathione-S-transferase pi isoform 1 (GSTP1) and crustacyanin are examples of lipocalin type CBPs that have been well characterised. These three complexes illustrate the complexities of the ligand-protein relationship and its importance for biological function.

The OCP was first described by Holt and Krogmann in 1981 and is one of few well-characterised carotenoprotein complexes. It is involved in nonphotochemicalquenching (NPQ) in cyanobacteria, which is crucial to the continuation of photosynthesis under high light conditions (Wilson et al., 2006). The $35 \mathrm{kDa}$ protein consists of an N-terminal all helical domain and a C-terminal nuclear transport factor 2 domain. The ligand, 3'-hydroxyechinenone $(\mathrm{hECN})$, is non-covalently bound within a hydrophobic pocket spanning both domains (Kerfeld et al., 2003). Upon binding, hECN adopts a 6-s-trans conformation in contrast to 6-s-cis when free in solution (Polívka et al., 2005).

Under conditions of high illumination, OCP is rapidly converted to a stable, red form of the complex (OCPr) (Wilson et al., 2008). The mechanism responsible for this conversion is unknown but structural rearrangements occur in both protein and carotenoid, though hECN remains in the trans conformation (Wilson et al., 2008). The changes are reversible however, as under low light conditions OCPr slowly reverts back to OCP. Mutagenesis experiments indicate that $\mathrm{OCPr}^{r}$ is the active form of the complex providing fluorescence-quenching activity to protect against photoinhibition (Wilson et al., 2008).

The $16 \mathrm{kDa}$ red carotenoid protein (RCP) was first identified during OCP purification (Holt \& Krogmann, 1981). It is the product of the removal of the entire Cterminal domain and a short fragment of the $\mathrm{N}$-terminus of OCP by proteolytic cleavage. This results in exposure

e-mail: jodi.pilbrow@otago.ac.nz

* Presented at the 16th International Symposium on Carotenoids, 17-22 July, 2011, Kraków, Poland

Abbreviations: AMD, age-related macular degeneration; CBPs, carotenoid-binding proteins; GST, glutathione-S-transferase; GSTP1 glutathione-S-transferase pi isoform 1; hECN, 3'-hydroxyechinenone; NPQ, nonphotochemical-quenching; OCP orange carotenoid protein; OCPr, red form of OCP; PAGE, polyacrylamide gel electrophoresis; ROS, reactive oxygen species; RCP, red carotenoid protein. 
of nearly half of the hECN molecule which re-isomerises to the 6-s-cis conformer (Chábera et al., 2011). However, RCP is a biologically relevant complex and not just an artefact of OCP purification. The exposed portion of hECN may insert into the lipid bilayer anchoring the protein to the membrane. Instead of light quenching, the primary role of the RCP is likely to be scavenging of reactive oxygen species (ROS) (Chábera et al., 2011).

The importance of carotenoids in vision has been well established. Retinal is a derivative of $\beta$-carotene and plays a central role in the visual process when bound to opsin, forming the visual pigment rhodopsin. There is also a high concentration of lutein and zeaxanthin within the foveal region of the retina (Bernstein et al., 2001). Glutathione-S-transferase (GST) proteins are well known for their role as phase II detoxification enzymes. However the report of a pi isoform, GSTP1, specifically binding to zeaxanthin in the human macula presented a new functional role for the ubiquitous protein family (Bhosale et al., 2004). This is the first report of GSTs interacting with carotenoids (Bhosale et al., 2004), though interaction with other small hydrophobic ligands through xenobiotic processing is common.

Although the specific function of GSTP1 in the macula remains to be elucidated, several roles have been postulated such as transport of xanthophylls to the site of deposition. Protein binding may increase the efficacy of ROS scavenging by zeaxanthin and GSTP1 may possess metabolic activity towards carotenoids (Bhosale et al., 2004). Furthermore, there is an inverse correlation between xanthophyll levels in the fovea and age-related macular degeneration (AMD), which is a leading cause of blindness amongst aged populations (Bernstein et al., 2002). This suggests carotenoid-protein interactions may have a pivotal role in maintaining eye health.

Crustacyanin is widespread amongst crustaceans, producing the dark blue/slate colouration of the carapace which is common in this phylum. Crustacyanin provides the molecular basis for camouflage patterning and pigmentation and therefore plays an essential role in the protection against predators (Rao, 1985). Crustacyanin exists in various different forms, such as $\alpha$-crustacyanin, a large complex of eight heterodimeric $\beta$-crustacyanin units (Buchwald \& Jenks, 1968). Two astaxanthin molecules interpenetrate the dimer interface (Cianci et al., 2002), but canthaxanthin is also tolerated (Velu et al., 2003; Czeczuga et al., 2005). Formation of this complex results in a red shift of over $100 \mathrm{~nm}$, in the absorption spectrum of the carotenoid (Britton \& Helliwell, 2008).

The large bathochromic shift is due to a combination of effects induced by ligand-protein interactions (Cianci et al., 2002). Firstly, the keto-groups at the 4 and 4 ' positions on the $\beta$-ionone rings of the carotenoids are held in a co-planar orientation with respect to the polyene chain, extending the conjugation of the chromophore. The carotenoids are also constrained so that the polyene chain is slightly bowed. However the greatest effect is attributed to the close proximity of the two carotenoid molecules at the dimer interface, which are minimally separated by just $7 \AA$ (Cianci et al., 2002). Thus protein interaction provides the biochemical basis for the change in colour from the red of free astaxanthin to darker hues that are more useful for camouflage.

Carotenoids play a pivotal role in the development of many marine invertebrates. Larvae inhabit the pelagic zone close to the sea surface and therefore the photoprotective and antioxidant activity provided by carotenoids is critical. Accordingly, carotenoids are often present in the gonads of marine invertebrates (Gilchrist \& Lee, 1972), such as the sea urchin. Echinenone is the most abundant carotenoid present in the sea urchin gonad accounting for up to $80 \%$ of the total (Griffiths \& Perrott, 1976; Tsushima \& Matsuno, 1990; Symonds et al., 2007; Symonds et al., 2009). The high concentration suggests that selective deposition of echinenone is occurring which would require the involvement of specific binding proteins.

Here we report the preliminary work on an echinenone-binding protein from the gonad of an indigenous New Zealand sea urchin, Evechinus chloroticus. A protein has been partially co-purified with a yellow pigment through anion exchange chromatography, monitoring the absorbance at 280, 450 and $474 \mathrm{~nm}$. The pigment was extracted from the sample by solvent phase separation and analysed by reversed phase-high performance liquid chromatography. The yellow pigment was identified as echinenone by comparison of the retention time with that of a commercial standard in accordance with the method reported by Symonds et al. (2007). The proteincarotenoid complex, which is readily soluble in aqueous media, was analysed by polyacrylamide gel electrophoresis (PAGE); a concentrated yellow band was visible in the gel following electrophoresis. This band was excised and electrophoresed onto SDS-PAGE resulting in the detection of a protein $12 \mathrm{kDa}$ in size.

It is clear that carotenoids have a variety of essential biological functions, although precise roles remain elusive in many instances. Complexes such as carotenoproteins are likely to be much more abundant in biology than the current literature suggests as there are few wellcharacterised examples. Although it is likely that they are widespread throughout nature they may not be extraordinarily abundant, particularly if acting as transporters as is typical of lipocalins (Flower, 1996). Low abundance of carotenoid-binding proteins may make initial detection and also purification difficult, as has been reported by Okoh et al. (1993) and Rao et al. (1997). In both studies a cellular $\beta$-carotene-binding protein could only be purified from liver tissue of rodents after feeding a $\beta$-carotene supplemented diet to increase the abundance of the carotenoid-binding protein isolated.

There are also practical difficulties to be overcome when working with carotenoprotein complexes. Though it may not be specifically associated with the complexes, lipid is omnipresent when working with carotenoids. Whilst this may be of functional importance in vivo it creates a further challenge to purification.

Despite these difficulties, great advances have been made in recent years with crystal structures solved for crustacyanin (Cianci et al., 2001; Cianci et al., 2002) and the orange carotenoid protein (Kerfeld et al., 2003). It is predicted that this trend will continue as the domain of carotenoid research is continually expanding and with it recognition that interaction with molecules such as lipids and proteins is fundamental to carotenoid biochemistry.

\section{Acknowledgements}

J Pilbrow was funded by a University of Otago Postgraduate Scholarship to undertake this research.

\section{REFERENCES}

Bernstein PS, Khachik F, Carvalho LS, Muir GJ, Zhao DY, Katz NB (2001) Identification and quantitation of carotenoids and their metabolites in the tissues of the human eve. Exp Eye Res 72: 215-223.

Bernstein PS, Zhao DY, Wintch SW, Ermakov IV, McClane RW, Gellermann W (2002) Resonance Raman measurement of macular carotenoids in normal subjects and in age-related macular degeneration patients. Ophthalmology 109: 1780-1787. 
Bhosale P, Larson AJ, Frederick JM, Southwick K, Thulin CD, Bernstein PS (2004) Identification and characterisation of a pi isoform of glutathione S-transferase as a zeaxanthin-binding protein in the macula of the human eye. I Biol Chem 279: 49447-49545.

Britton G (1995) Structure and properties of carotenoids in relation to function. FASEB J 9: 1551-1558.

Britton G, Liaaen-Jensen S, Pfander H, eds, (2004) Carotenoids Handbook. Birkhäuser Verlag, Basel.

Britton G (2008) Functions of intact carotenoids. In Carotenoids Vol.4 Natural Functions. Britton G, Liaaen-Jensen S, Pfander H, eds, pp 189-211. Birkhäuser Verlag, Basel.

Britton G, Halliwell JR (2008) Carotenoid-protein interactions. In Carotenoids Vol.4 Natural Functions. Britton G, Liaaen-Jensen S, Pfander H, eds, pp 99-118. Birkhäuser Verlag, Basel.

Buchwald M, Jencks WP (1968) Properties of the crustacyanins and the yellow lobster shell pigment. Biochemistry 7: 844-859.

Chábera P, Durchan M, Shih PM, Kerfeld CA, Polívka T (2011) Excited-state properties of the $16 \mathrm{kDa}$ red carotenoid protein from Arthrospira maxima. Biochim Biophys Acta 1807: 30-35.

Cianci M, Rizkallah PJ, Olczak A, Raftery J, Chayen NE, Zagalsky PF, Helliwell JR (2001) Structure of lobster apocrustacyanin $A_{1}$ using softer X-rays. Acta Cryst D 57: 1219-1229.

Cianci M, Rizkallah PJ, Olczak A, Radtery J, Chayen NE, Zagalsky PF, Helliwell JR (2002) The molecular basis of the colouration mechanism in lobster shell $\beta$-crustacyanin at $3.2-\AA$ resolution. Proc Nalt Acad Sci 99: 9795-9800.

Czeczuga B, Czeczuga-Semeniuk E, Semeniuk A (2005) Carotenoids and carotenoproteins in Asellus aquaticus L. (Crustacea: Isopoda). Folia biologica (Krakow) 53: 109-114.

Erdman JW, Bierer TL, Gugger ET (1993) Absorption and transport of carotenoids. Anal New York Acad Sci 691: 76-85.

Flower DR (1996) The lipocalin protein family: structure and function. Biochem J 318: 1-14.

Gilchrist BM, Lee WL (1972) Carotenoid pigments and their possible role in reproduction in the sand crab, Emerita analoga. Comp Biochem Physiol B 42: 263-294.

Griffiths M, Perrott P (1976) Seasonal changes in the carotenoids of the sea urchin Strongylocentrotus drobachiensis. Comp Biochem Physiol 55B: 435-441.

Holt TK, Krogmann DW (1981) A carotenoid protein from cyanobacteria. Biochim Biophys Acta 637: 408-414.
Kerfeld CA, Sawaya MR, Brahmandam V, Cascio D, Ho KK, Trevithick-Sutton CC, Krogmann DW, Yeates TO (2003) The crystal structure of cyanobacterial water-soluble carotenoid-binding protein. Structure 11: 55-65.

Okoh C, Mychkovsky I, Lakshman MR (1993) Isolation and some properties of a carotenoid-protein complex from rat liver. I Nutr Biochem 4: 569-575.

Polívka T, Kerfeld CA, Pascher T, Sundstrom V (2005) Spectroscopic properties of the carotenoid 3'-hydroxyechenone in the orange carotenoid protein from the cyanobacterium Arthrospira maxima. Biochemistry 44: 3994-4003.

Rao KR (1985) Pigmentary effectors. In Integuments, pigments and hormonal processes. Bliss DE, Mantel LH, eds, pp 395-462. Academic Press, New York.

Rao MN, Ghosh P, Lakshman MR (1997) Purification and partial characterisation of a cellular carotenoid-binding protein from Ferret liver. J Biol Chem 272: 24455-24460.

Symonds RC, Kelly MS, Caris-Veyrat C, Young AJ (2007) Carotenoids in the sea urchin Paracentrotus lividus: Occurrence of 9'-cis-echinenone as the dominant carotenoid in gonad colour determination. Comp Biochem Physiol B 148: 432-444.

Symonds RC, Kelly MS, Suckling CC, Young AJ (2009) Carotenoids in the gonad and gut of the edible sea urchin Psammechinus miliaris. Aquaculture 288: 120-125.

Tsushima M, Matsuno T (1990) Comparative biochemical studies of carotenoids in sea urchins-I. Comp Biochem Physiol 96B: 801-810.

Velu CS, Czeczuga B, Munuswamy N (2003) Carotenoprotein complexes in entomostracan crustaceans (Streptocephalus dichotomus and Monina micrura). Comp Biochem Physiol B 135: 35-42.

Wilson A, Ajlani G, Verbavatz J-M, Vass I, Kerfeld CA, Kirilovsky D (2006) A soluble carotenoid protein involved in phycobilisomerelated energy dissipation in cyanobacteria. Plant Cell 18: 992-1007.

Wilson A, Punginelli C, Gall A, Bonetti C, Alexandre M, Routaboul J-M, Kerfeld C, van Grondelle R, Robert B, Kennis JTM, Kirilovsky D (2008) A photoactive carotenoid protein acting as a light intensity sensor. Proc Natl Acad Sci USA 105: 12075-12080.

Zagalsky PF (1976) Carotenoid-protein complexes. Pure \& Appl Chem 47: 103-120. 